\title{
OBTENÇÃO DE CARVÃO ATIVADO A PARTIR DO BAGAÇO DA CASCA DE ACÁCIA-NEGRA E SUA APLICAÇÃO COMO ADSORVENTE
}

\author{
V. C. ARABIDIAN ${ }^{1}$, S. F. LÜTKE ${ }^{1}$, F. S. GRASEL ${ }^{2}$, T. R. S. CADAVAL Jr ${ }^{1}$ e L. A. A. \\ PINTO $^{1}$ \\ ${ }^{1}$ Universidade Federal do Rio Grande, Escola de Química e Alimentos \\ ${ }^{2}$ TANAC S.A. \\ E-mail para contato: viarabidian@hotmail.com
}

\begin{abstract}
RESUMO - No presente trabalho, foram produzidos carvões ativados a partir do bagaço da casca de acácia-negra por ativação química utilizando $\mathrm{ZnCl}_{2}$. Para verificar a significância dos fatores de estudo, foi realizado um delineamento experimental fatorial fracionário. Os carvões ativados obtidos foram avaliados quanto a capacidade de adsorção dos corantes azul de metileno e amarelo tartrazina. Os fatores que mais influenciaram a capacidade de adsorção foram a temperatura de carbonização, o tempo de carbonização e o percentual de agente ativante. Os fatores temperatura de carbonização e percentual de agente ativante apresentaram efeito positivo na capacidade de adsorção de ambos os corantes. Já o tempo de carbonização apresentou efeito negativo para a capacidade de adsorção do corante azul de metileno e efeito positivo para a capacidade de adsorção do corante amarelo tartrazina. As maiores capacidades de adsorção dos carvões ativados foram de $87,74 \mathrm{mg} \mathrm{g}^{-1}$ e de $27,70 \mathrm{mg} \mathrm{g}^{-1}$ para o azul de metileno e para o amarelo tartrazina, respectivamente.
\end{abstract}

\section{INTRODUÇÃO}

O carvão ativado é um material carbonáceo, que possui uma elevada área superficial e uma estrutura de poros bem desenvolvida (micro, meso e macroporos), podendo conter a presença de grupos funcionais em sua superfície (Bahtnagar et al., 2013). Devido a estas características, o carvão ativado é um excelente material para ser utilizado em operações de adsorção, sendo um dos adsorventes mais comumente empregados no tratamento de efluentes contendo corantes (Gopinathan et al., 2017).

No entanto, os carvões ativados comerciais disponíveis ainda são considerados de elevado custo, uma vez que os materiais precursores empregados para sua produção são relativamente caros (Chen et al., 2010). Nesse contexto, a utilização de resíduos lignocelulósicos como materiais precursores para produção de carvão ativado vem desempenhando um importante papel, uma vez que se tratam de matérias-primas abundantes e de baixo custo, tornando-se uma alternativa economicamente viável aos carvões ativados comerciais produzidos atualmente (Demirbas, 2009; Deng et al., 2011). 
Um material precursor promissor para a produção de carvão ativado é o bagaço da casca de acácia-negra. A extração do tanino a partir da casca de acácia-negra gera uma grande quantidade de bagaço, o qual acaba sendo destinado à compostagem orgânica, combustão ou dispostos em aterros, gerando custos para as indústrias (Linhares et al., 2016). Dessa forma, torna-se interessante a busca de alternativas que visem transformar esse resíduo, agregando valor ao mesmo.

O objetivo do presente trabalho foi produzir carvões ativados, em diferentes condições, a partir do bagaço da casca de acácia-negra e aplicá-los na adsorção dos corantes azul de metileno e amarelo tartrazina, comparando-os com o carvão ativado comercial.

\section{MATERIAL E MÉTODOS}

\subsection{Material}

O bagaço da casca de acácia-negra, utilizado como material precursor para a produção do carvão ativado foi cedido pela empresa TANAC/RS, sendo este proveniente do processo de extração de taninos.

Os corantes utilizados nos ensaios de adsorção foram o azul de metileno (AM) (índice de cor 52015, massa molar 319,8 $\mathrm{g} \mathrm{mol}^{-1}, \lambda \max 664 \mathrm{~nm}$, pureza 99\%), fornecido pela empresa Plury Química (Brasil) e o amarelo tartrazina (AT) (índice de cor 19140, massa molar 534,4 g mol-1, $\lambda \max 425 \mathrm{~nm}$, pureza 85\%), fornecido pela empresa Duas Rodas Ltda. (Brasil).

Para comparação das capacidades de adsorção dos carvões ativados (CA) obtidos, foi utilizando carvão ativado comercial (CAC), fornecido pela empresa Vetec (Brasil), o qual possui diâmetro médio de partícula $(\mathrm{Dp})$ de $68 \pm 6 \mu \mathrm{m}$, área superficial especifica (As) de $650,0 \pm 10,5 \mathrm{~m}^{2} \mathrm{~g}^{-1}$, esfericidade $(\varnothing)$ de $0,75 \pm 0,05$ e massa específica $(\rho)$ de $1100 \pm 10 \mathrm{~kg} \mathrm{~m}^{-}$ 3

\subsection{Preparação do Material Precursor}

O bagaço da casca de acácia-negra foi triturado em moinho de facas (modelo Willey, $n^{\circ} 3$, EUA) e lavado com água à quente e com etanol à quente, sendo ambas as lavagens realizadas sob agitação constante por $2 \mathrm{~h}$, para remover os resíduos de taninos e outras impurezas solúveis. Após as lavagens, o bagaço foi filtrado a vácuo, seco em estufa a $40{ }^{\circ} \mathrm{C}$ por 24 h e separado entre peneiras (série Tyler), sendo utilizada a fração passante na malha 35 mesh e retira na malha 48 mesh.

\subsection{Produção do Carvão Ativado}

Para a produção do carvão ativado, o bagaço da casca de acácia-negra foi inicialmente impregnado com $\mathrm{ZnCl}_{2}$. Para a impregnação, o bagaço foi imerso no agente ativante previamente diluído em água deionizada e mantido sob agitação constante a temperatura ambiente. Após a impregnação, o material foi filtrado a vácuo, seco em estufa a $110^{\circ} \mathrm{C}$ por 24 $\mathrm{h}$ e submetido à carbonização em forno mufla. Para o estudo das condições de produção de carvão ativado a partir do bagaço da casca de acácia-negra, foi realizado um delineamento experimental fatorial fracionário $2^{4-1}$. Os fatores de estudo foram: temperatura de 
carbonização $(\mathrm{Tc})$, tempo de carbonização $\left(\mathrm{t}_{\mathrm{C}}\right)$, percentual de agente ativante em relação a massa do material precursor (\%AT) e tempo de imersão no agente ativante $\left(\mathrm{t}_{\mathrm{I}}\right)$, de acordo com a Tabela 1. As respostas foram as capacidades de adsorção no equilíbrio $\left(\mathrm{q}_{\mathrm{e}}\right)$ dos corantes estudados.

Tabela 1 - Matriz do delineamento fatorial fracionário $2^{4-1}$ para a produção de carvão ativado, na forma codificada e com os valores reais.

\begin{tabular}{|c|c|c|c|c|}
\hline EXP & $\mathrm{T}_{\mathrm{C}}\left({ }^{\circ} \mathrm{C}\right)$ & $\mathrm{t}_{\mathrm{C}}(\mathrm{h})$ & $\%$ AT $(\mathrm{m} / \mathrm{m})$ & $\mathrm{t}_{\mathrm{I}}(\mathrm{h})$ \\
\hline \hline 1 & $-1(500)$ & $-1(2)$ & $-1(5)$ & $-1(12)$ \\
\hline 2 & $+1(700)$ & $-1(2)$ & $-1(5)$ & $+1(24)$ \\
\hline 3 & $-1(500)$ & $+1(4)$ & $-1(5)$ & $+1(24)$ \\
\hline 4 & $+1(700)$ & $+1(4)$ & $-1(5)$ & $-1(12)$ \\
\hline 5 & $-1(500)$ & $-1(2)$ & $+1(20)$ & $+1(24)$ \\
\hline 6 & $+1(700)$ & $-1(2)$ & $+1(20)$ & $-1(12)$ \\
\hline 7 & $-1(500)$ & $+1(4)$ & $+1(20)$ & $-1(12)$ \\
\hline 8 & $+1(700)$ & $+1(4)$ & $+1(20)$ & $+1(24)$ \\
\hline
\end{tabular}

Para remover o excesso de $\mathrm{Zn}$ e reduzir o teor de cinzas, os carvões ativados obtidos foram lavado com $\mathrm{HCl} 0,5 \mathrm{M}$ a $95^{\circ} \mathrm{C}$ por 30 min sob agitação constante. Após foram filtrados a vácuo e lavados diversas vezes com água deionizada a quente, até atingir $\mathrm{pH}$ neutro e não serem detectados íons cloreto. O material resultante foi seco em estufa a $110^{\circ} \mathrm{C}$ por $24 \mathrm{~h}$.

\subsection{Ensaios de adsorção}

Os ensaios de adsorção foram realizados utilizando-se soluções de $100 \mathrm{mg} \mathrm{L}^{-1}$ dos corantes, na temperatura de $25^{\circ} \mathrm{C}$, sob agitação de $150 \mathrm{rpm}$ e pH 6,5 (pH da própria solução dos corantes). $\mathrm{O}$ pH da solução não se alterou durante a operação. $\mathrm{O}$ adsorvente foi adicionado na concentração de $1 \mathrm{~g} \mathrm{~L}^{-1}$ e o tempo de contato foi de $24 \mathrm{~h}$. Todos os experimentos foram realizados em triplicata. A quantidade de corante remanescente na fase aquosa foi determinada por espectrofotometria (Quimis, Q108, Brasil). A capacidade de adsorção no equilíbrio $\left(\mathrm{q}_{\mathrm{e}}\right)$ foi determinada pela Equação 1 .

$$
q_{e}=\left(\frac{C_{0}-C_{e}}{m}\right) V
$$

onde $\mathrm{C}_{\mathrm{o}}$ e $\mathrm{C}_{\mathrm{e}}$ são as concentrações do adsorbato inicial e no equilíbrio, respectivamente (mg $\mathrm{L}^{-1}$ ), $\mathrm{m}$ é a massa do adsorvente (g) e V é o volume da solução (L).

\section{RESULTADOS E DISCUSSÃO}

Os resultados das capacidades de adsorção do corante AM para os carvões ativados obtidos de acordo com a matriz do delineamento experimental fatorial fracionário $2^{4-1}$ são apresentados na Tabela 2 e o diagrama de Pareto, onde pode ser observada a significância dos fatores de estudo, é mostrado na Figura 1. 
Tabela 2 - Matriz para a capacidade de adsorção do corante AM.

\begin{tabular}{|c|c|c|c|c|c|}
\hline $\mathrm{CA}$ & $\mathrm{T}_{\mathrm{C}}\left({ }^{\circ} \mathrm{C}\right)$ & $\mathrm{t}_{\mathrm{C}}(\mathrm{h})$ & $\% \mathrm{AT}(\mathrm{m} / \mathrm{m})$ & $\mathrm{t}_{\mathrm{I}}(\mathrm{h})$ & $\mathrm{q}\left(\mathrm{mg} \mathrm{g}^{-1}\right)^{*}$ \\
\hline \hline 1 & $-1(500)$ & $-1(2)$ & $-1(5)$ & $-1(12)$ & $24,33 \pm 0,54$ \\
\hline 2 & $+1(700)$ & $-1(2)$ & $-1(5)$ & $+1(24)$ & $50,82 \pm 0,74$ \\
\hline 3 & $-1(500)$ & $+1(4)$ & $-1(5)$ & $+1(24)$ & $16,23 \pm 0,60$ \\
\hline 4 & $+1(700)$ & $+1(4)$ & $-1(5)$ & $-1(12)$ & $45,86 \pm 0,64$ \\
\hline 5 & $-1(500)$ & $-1(2)$ & $+1(20)$ & $+1(24)$ & $38,59 \pm 0,57$ \\
\hline 6 & $+1(700)$ & $-1(2)$ & $+1(20)$ & $-1(12)$ & $84,74 \pm 0,63$ \\
\hline 7 & $-1(500)$ & $+1(4)$ & $+1(20)$ & $-1(12)$ & $28,06 \pm 0,70$ \\
\hline 8 & $+1(700)$ & $+1(4)$ & $+1(20)$ & $+1(24)$ & $83,46 \pm 0,47$ \\
\hline
\end{tabular}

*média \pm desvio padrão $(\mathrm{n}=3)$.

Figura 1 - Diagrama de Pareto para a resposta capacidade de adsorção do corante AM

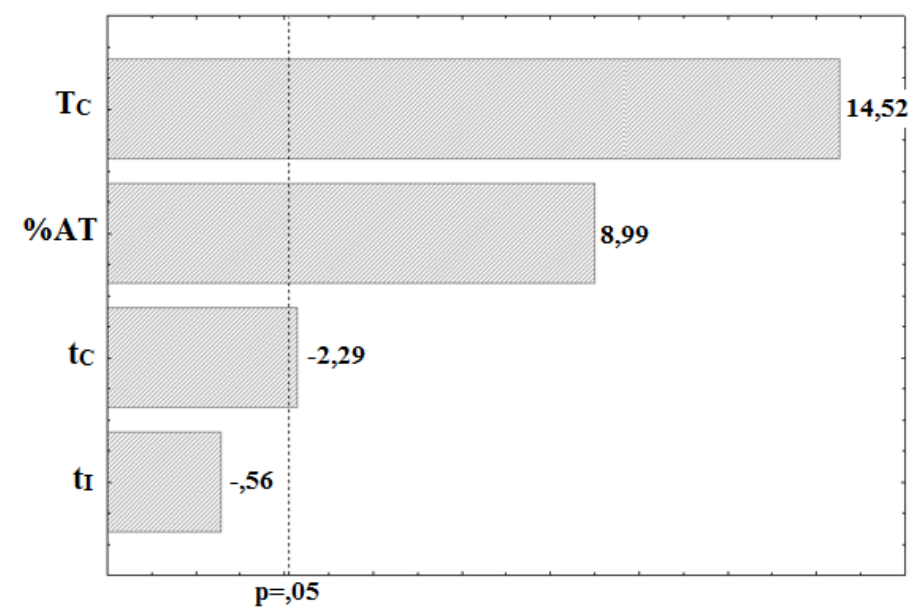

Efeitos Estimados Padronizados (Valores Absolutos)

Pode-se observar na Figura 1 que variáveis temperatura de carbonização $\left(\mathrm{T}_{\mathrm{C}}\right)$, tempo de carbonização $\left(\mathrm{t}_{\mathrm{C}}\right)$ e percentual de agente ativante em relação ao material precursor $(\% \mathrm{AT})$ foram significativas ao nível de $95 \%$ de confiança $(p<0,05)$. As variáveis temperatura de carbonização e percentual de agente ativante apresentaram efeito positivo na capacidade de adsorção, já a variável tempo de carbonização apresentou efeito negativo.

As capacidades de adsorção do corante AT para os carvões ativados obtidos de acordo com a matriz do delineamento experimental fatorial fracionário $2^{4-1}$ são apresentados na Tabela 3 e o diagrama de Pareto é mostrado na Figura 2.

Tabela 3 - Matriz para a capacidade de adsorção do corante AT.

\begin{tabular}{|c|c|c|c|c|c|}
\hline $\mathrm{CA}$ & $\mathrm{T}_{\mathrm{C}}\left({ }^{\circ} \mathrm{C}\right)$ & $\mathrm{t}_{\mathrm{C}}(\mathrm{h})$ & $\% \mathrm{AT}(\mathrm{m} / \mathrm{m})$ & $\mathrm{t}_{\mathrm{I}}(\mathrm{h})$ & $\mathrm{q}\left(\mathrm{mg} \mathrm{g}^{-1}\right)^{*}$ \\
\hline \hline 1 & $-1(500)$ & $-1(2)$ & $-1(5)$ & $-1(12)$ & $12,35 \pm 0,50$ \\
\hline 2 & $+1(700)$ & $-1(2)$ & $-1(5)$ & $+1(24)$ & $16,69 \pm 0,52$ \\
\hline 3 & $-1(500)$ & $+1(4)$ & $-1(5)$ & $+1(24)$ & $19,05 \pm 0,82$ \\
\hline 4 & $+1(700)$ & $+1(4)$ & $-1(5)$ & $-1(12)$ & $20,90 \pm 0,66$ \\
\hline 5 & $-1(500)$ & $-1(2)$ & $+1(20)$ & $+1(24)$ & $14,68 \pm 0,62$ \\
\hline 6 & $+1(700)$ & $-1(2)$ & $+1(20)$ & $-1(12)$ & $16,51 \pm 0,48$ \\
\hline 7 & $-1(500)$ & $+1(4)$ & $+1(20)$ & $-1(12)$ & $13,95 \pm 0,66$ \\
\hline 8 & $+1(700)$ & $+1(4)$ & $+1(20)$ & $+1(24)$ & $27,70 \pm 0,40$ \\
\hline
\end{tabular}

*média \pm desvio padrão $(n=3)$. 
Figura 2 - Diagrama de Pareto para a resposta capacidade de adsorção do AT.

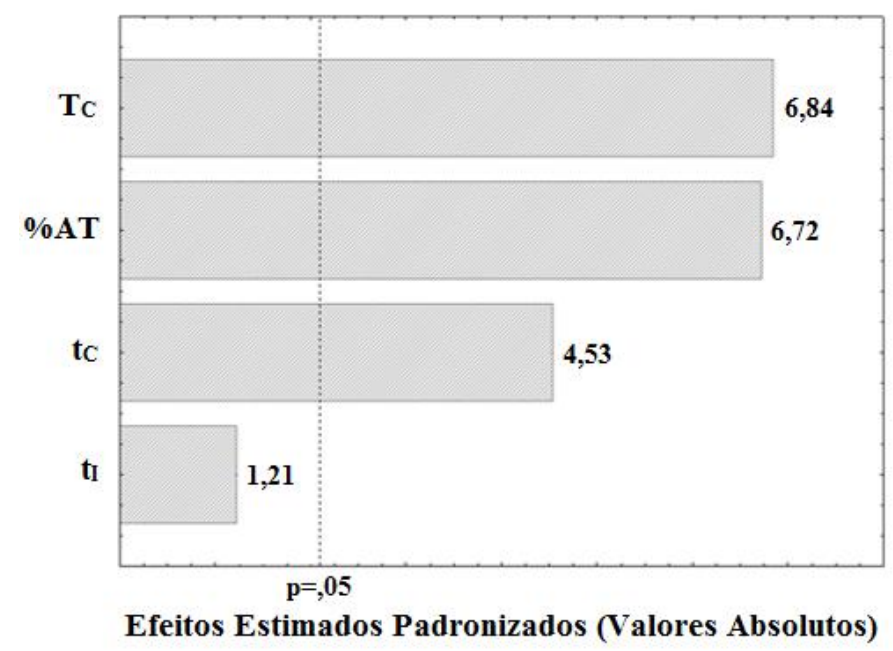

Pode ser observado na Figura 2 que as variáveis temperatura de carbonização $\left(\mathrm{T}_{\mathrm{C}}\right)$, percentual de agente ativante em relação à massa do material precursor (\%AT) e tempo de carbonização $\left(\mathrm{t}_{\mathrm{C}}\right)$ foram significativas ao nível de $95 \%$ de confiança $(\mathrm{p}<0,05)$, sendo que todas apresentaram efeito positivo na capacidade de adsorção.

Quanto a temperatura de carbonização, foi observado que o aumento desta, de 500 para $700{ }^{\circ} \mathrm{C}$, ocasionou um aumento na capacidade de adsorção de ambos os corantes. Esse comportamento deve-se ao fato de que com aumento da temperatura de carbonização, mais matéria volátil foi liberada, resultando no desenvolvimento de um maior número de poros (Mohanty et al., 2005). Em relação ao tempo de carbonização, o aumento de 2 para $4 \mathrm{~h}$ ocasionou a diminuição da capacidade de adsorção do corante AM e o aumento da capacidade de adsorção do corante AT. Esse comportamento pode ser devido a eliminação, em maiores tempos de carbonização, de grupos funcionais presentes na superfície do carvão ativado, como os grupos quinona e lactona, os quais possuem maior interação com o corante AM. O aumento do percentual de agente ativante, de 5 para $20 \%$, levou a um aumento da capacidade de adsorção de ambos os corantes. A impregnação de $\mathrm{ZnCl}_{2}$ no material precursor leva a dilatação da estrutura da celulose. Dessa forma, um maior percentual de $\mathrm{ZnCl}_{2}$ leva a formação de mais cavidades (Demiral e Demiral, 2008). O tempo de imersão do material precursor no agente ativante não influenciou significativamente a capacidade de adsorção dos corantes. Isso deve-se, provavelmente, ao fato de que o tempo de $12 \mathrm{~h}$ foi suficiente para que o agente ativante impregnasse no material precursor.

A Tabela 4 apresenta uma comparação das capacidade de adsorção do CA 6 e do CA 8, que apresentaram as melhores capacidades de adsorção dos corantes AM e AT, respectivamente, com o carvão ativado comercial (CAC). O CA 6 apresentou-se como um adsorvente promissor para remoção do corante AM de meios aquosos, uma vez que sua capacidade de adsorção foi próxima a do CAC. Já o CA 8 mostrou-se menos eficiente na remoção do corante AT, uma vez que sua capacidade de adsorção foi consideravelmente inferior quando comparado a capacidade de adsorção do CAC para esse mesmo corante. 
Tabela 4 - Comparação da capacidades de adsorção dos CA obtidos com o CAC.

\begin{tabular}{l}
\begin{tabular}{|c|c|c|}
\hline \multirow{2}{*}{ Adsorvente } & \multicolumn{2}{|c|}{$\mathrm{q}\left(\mathrm{mg} \mathrm{g}^{-1}\right)^{*}$} \\
\cline { 2 - 3 } & AM & AT \\
\hline \hline CA 6 & $84,74 \pm 0,63$ & - \\
\hline CA 8 & - & $27,70 \pm 0,40$ \\
\hline CAC & $98,26 \pm 0,71$ & $71,41 \pm 0,58$ \\
\hline
\end{tabular} * média \pm desvio padrão $(\mathrm{n}=3)$. \\
\hline
\end{tabular}

\section{CONCLUSÕES}

Os resultados do planejamento fatorial fracionário indicaram que os fatores significativos na produção de carvão ativado a partir do bagaço da casca de acácia-negra foram temperatura de carbonização, tempo de carbonização e percentual de agente ativante. Os fatores temperatura de carbonização e percentual de agente ativante apresentaram efeito positivo na capacidade de adsorção de ambos os corantes. Já o fator tempo de carbonização apresentou efeito negativo na capacidade de adsorção do AM e efeito positivo a capacidade de adsorção do AT. Comparativamente ao carvão ativado comercial (CAC), o CA obtido a partir do bagaço da casca de acácia mostrou-se promissor na adsorção do corante AM e uma baixa eficiência na adsorção do corante AT.

\section{REFERÊNCIAS}

BHATNAGAR, A.; HOGLAND, W.; MARQUES, M.; SILLANPAA, M. An overview of the modification methods of activated carbon for its water treatment applications. Chem. Eng. J., v. 219, p. 499-511, 2013.

CHEN, S.; ZHANG, J.; ZHANG, C.; YUE, Q.; LI, Y.; LI, C. Equilibrium and kinetic studies of methyl orange and methyl violet adsorption on activated carbon derived from Phragmites australis. Desalination, v. 242, p. 149-156, 2010.

DEMIRAL, H.; DEMIRAL, I. Surface properties of activated carbon prepared from wastes. Surf. Interface Anal., v. 40, p. 612-615, 2008.

DEMIRBAS, A. Agricultural based activated carbons for the removal of dyes from aqueous solutions: A review. J. Hazard. Mat., v. 167, p. 1-9, 2009.

DENG, H.; LU, J.; LI, G.; ZHANG, G.; WANG, X. Adsorption of methylene blue on adsorbent materials produced from cotton stalk. Chem. Eng. J., v. 172, p. 326-334, 2011.

GOPINATHAN, R.; BHOWAL, A.; GARLAPATI, C. Thermodynamic study of some basic dyes adsorption from aqueous solutions on activated carbon and new correlations. J. Chem. Thermodyn., v. 107, p.182-188, 2017.

LINHARES, F. A., MARCÍLIO, N. R., MELO, P. J. Estudo da produção de carvão ativado a partir do resíduo de casca da acácia negra com e sem ativação química. Sci. Cum Ind., v. 4, p. 74-79, 2016.

MOHANTY, K.; JHA, M.; MEIKAP, B. C.; BISWAS, M. N. Preparation and characterization of activated carbons from Terminalia arjuna nut with zinc chloride activation for the removal of phenol from wastewater. Ind. Eng. Chem. Res., v. 44, 4128-4138, 2005. 